\title{
Enhanced Solubility and Drug Release of Ketoprofen Using Lyophilized Bovine Serum Albumin Solid Dispersion
}

\author{
Meenakshi Bhatia ${ }^{*}$, Rupa Devi ${ }^{1}$ \\ 1 Guru Jambheshwar University of Science and Technology, Pharmaceutical Sciences, Hisar, India
}

\begin{abstract}
Solid dispersions have been proved to be an effective method for the improvement of solubility and bioavailability of poorly water-soluble drugs. The study was designed to demonstrate the potential of ketoprofen loaded BSA solid dispersions on the solubility \& in-vitro release of ketoprofen.
\end{abstract}

Ketoprofen-BSA solid dispersions were prepared by the freeze-drying method. A 2-factor, 3-level central composite experimental design was used to study the effect of varying concentration of BSA and ketoprofen on drug solubility \& in-vitro drug release.

The combined effect of concentration of BSA \& ketoprofen on \% release and solubility exhibited a linear relationship between independent and dependent variables, suggesting that higher level of BSA \& ketoprofen favours the expedited release and solubility.

Bovine serum albumin may be explored as a carrier for the preparation of solid dispersion for the enhancement of solubility and in-vitro drug release of BCS class II drug ketoprofen.

Keywords: Bovine serum albumin, Ketoprofen, Solid dispersion, Lyophilization.

\section{INTRODUCTION}

Biopharmaceutical classification system (BCS) divided the active pharmaceutical ingredient into four classes (I, II, III, IV) based on their solubility in water and membrane permeability. In recent years class II drugs (having low solubility \& high permeability) have appeared oft times as candidate compound for development in drug discovery stage ${ }^{\mathbf{1}}$. Various techniques including cyclodextrins complexes ${ }^{2}$, nanoparticle technology ${ }^{3}$, self emulsifying drug deliv-

*Corresponding author: Meenakshi Bhatia, e-mail: meenaxibhatia@gmail.com

(Received 08 September 2018, accepted 19 October 2018) 
ery systems (SEDDS) ${ }^{4}$, liposomes ${ }^{5}$, salt formation ${ }^{6}$, use of surfactant "micellization"7, amorphisation ${ }^{8}$ and solid dispersion etc., have been attempted to overcome the poor solubility issues. Nowadays, solid dispersion has become the synonym for the solubility enhancement of poorly water-soluble drugs. Solid dispersion of poorly soluble drugs in water soluble carriers to improve the solubility and dissolution was reported decades ago ${ }^{9}$. Since then, the solid dispersion is explored colossally. Solid dispersion as group of solid products made up of both hydrophilic matrix and hydrophobic drug. The matrix can be either amorphous or crystalline ${ }^{\mathbf{1 0}}$. For the improvement of bioavailability and dissolution rate of poorly water-soluble drugs use of various hydrophilic carriers like polyethylene glycol (PEG) ${ }^{11}$, hydroxypropylmethyl cellulose (HPMC) ${ }^{12}$, polyvinylpyrrolidone (PVP) ${ }^{13}$, hydroxypropyl cellulose ${ }^{14}$, hydroxypropylmethyl cellulose phthalate ${ }^{15}$, gums ${ }^{16}$, $\operatorname{sugar}^{17}$, mannitol ${ }^{18}$, urea $^{19}$, gelucires ${ }^{20}$, eudragits $^{21}$, chitosan ${ }^{22}$, sodium starch glycolate ${ }^{23}$ and pregelatinized starch etc. has been investigated vastly ${ }^{24}$.

Bovine serum albumin (BSA) also known as "Fraction V" is a serum albumin protein derived from cows is the most abundant protein in plasma that is also extensively used in pharmaceutical industry because of its low cost, ease of purification, biocompatibility and biodegradability and also due to its chemical similarity to human albumin ${ }^{25}$. BSA plays the role of an "in-vivo solubilizing agent" that enables the solubilisation of a wide range of biomolecules and drugs in plasma (a hydrophilic medium) ${ }^{\mathbf{2 6}, 27}$. Albumin has varied physiological functions like maintaining plasma osmotic pressure and neutralising free radicals $^{\mathbf{2 8 , 2 9}}$. The solubility enhancement properties of albumin are generally due to its incredible ability to form reversible binding complexes with ligands mainly by hydrophobic and electrostatic interaction ${ }^{\mathbf{2 6}, 30}$. This makes the bound molecule to flow in the blood at a higher concentration than its initial solubility. It possesses overall negative charge at physiological $\mathrm{pH}$ that endorses the binding of anionic molecules (weak acids) \& hydrophobic molecules ${ }^{27,30}$. Moreover, it also contains a no. of free amino and carboxyl groups amenable to form highly soluble salts with acidic or basic drugs, respectively. This exceptional capacity of albumin to dissolve poorly soluble drugs is explored in this piece of research.

The aim of present study is to predominantly investigate the use of BSA as a carrier for solubility enhancement of ketoprofen. Ketoprofen is a non-steroidal anti-inflammatory drug belonging to class II that is having aqueous solubility of $0.5 \mu \mathrm{g} / \mathrm{ml}$. Ketoprofen binds with albumin molecule as its chemical structure is adaptable to form salt bridges with albumin amino groups. In this study, solid dispersion is prepared by freeze-drying or lyophilization technique. Ketoprofen-BSA solid dispersions are characterized by Fourier transform infrared 
spectroscopy (FT-IR), X-ray diffraction (XRD), differential scanning calorimetry (DSC) and scanning electron microscopy (SEM) studies. In addition, the solubility and in-vitro release profile of ketoprofen are also evaluated.

\section{METHODOLOGY}

\section{Materials}

Ketoprofen was obtained as a gift sample from Infinity Laboratories, Behra (India). Bovine serum albumin (BSA), ethanol, sodium chloride, potassium chloride, di-sodium hydrogen orthophosphate, potassium di-hydrogen orthophosphate was procured from Hi-Media lab. Pvt. Ltd. All other chemicals \& reagents used in the study were of analytical grade and used as received.

\section{Preparation of freeze dried solid dispersion}

Ketoprofen (0.1-0.5\% w/v in aqueous ethanol) was added to BSA (0.1-2\% w/v) that results in the formation of colloidal solution or colloidal suspension depending on the concentration of ketoprofen. The resulting solution/suspension was kept at $-80^{\circ} \mathrm{C}$ for $4 \mathrm{hrs}$ and lyophilized for $48 \mathrm{hrs}$ in a lab scale lyophilizer.

\section{Experimental design}

A 2-factor, 3-level central composite experimental design was used to prepare solid dispersions. Based on preliminary trials, concentration of BSA $\left(\mathrm{X}_{1}\right)$ \& concentration of ketoprofen $\left(\mathrm{X}_{2}\right)$ were selected as independent variables while solubility $\left(\mathrm{Y}_{1}\right)$ \& in-vitro release $\left(\mathrm{Y}_{2}\right)$ were selected as the dependent variables (Table 1). The experimental design and statistical analysis of the data was carried out as per the design protocol by using Design Expert Software (Version 11).

\section{Determination of drug content}

The different solid dispersion (SD) batches and physical mixture (PM) equivalent to 10mg of ketoprofen were dissolved separately in $25 \mathrm{ml}$ of phosphate buffer ( $\mathrm{pH}$ 7.4). The solution was filtered and further diluted appropriately. Samples were filtered through $0.45 \mu \mathrm{m}$ milipore filters and analyzed by UVvisible spectrophotometer at $260 \mathrm{~nm}$.

\section{Characterisation}

\section{Fourier Transform Infrared Spectroscopy (FT-IR)}

Fourier Transform Infrared Spectroscopy was used to detect interaction between drug and carrier. FTIR spectral analysis of ketoprofen, BSA, PM and SD were done by FT-IR (FT-IR Spectrophotometer Perkin-Elmer BX II) in the range of $4000-400 \mathrm{~cm}^{-1}$ using $\mathrm{KBr}$ pellets. 


\section{$X$-ray diffraction analysis (XRD)}

The X-ray diffractometry was carried out for phase identification of the materials. The XRD spectra of ketoprofen, BSA, PM and SD were carried out using an $\mathrm{X}$-ray diffractometer (Miniflex 2, Rigaku, Japan) at room temperature and at $30 \mathrm{kV}$. The scanning diffraction angle $(2 \theta)$ ranged from $\mathrm{o}^{\circ}$ to $80^{\circ}$.

\section{Differential scanning calorimetry (DSC)}

Differential scanning calorimetric thermogram of ketoprofen, BSA, PM and SD were recorded using differential scanning calorimeter (SDT Q600 V20.9 Build $20 \mathrm{TA}$ instrument, USA $)$ in the temperature range of $\left(25^{\circ} \mathrm{C}-300^{\circ} \mathrm{C}\right)$ at a heating rate of $10^{\circ} \mathrm{C} / \mathrm{min}$ in nitrogen atmosphere.

\section{Scanning electron microscopy (SEM)}

The shape and surface morphology of SD were examined using scanning electron micro-scope (JSM-610o scanning microscopy, Japan) The sample were coated with gold and mounted on aluminium stub containing double adhesive carbon tape. The photographs were taken at acceleration voltages of $10 \mathrm{kV}$.

\section{Solubility}

The solubility of ketoprofen drug was determined by taking pure drug, PM and solid dispersion equivalent to $10 \mathrm{mg}$ ketoprofen in $10 \mathrm{ml}$ of distilled water and was kept for $48 \mathrm{hrs}$ on shaker at room temperature $\left(25^{\circ} \mathrm{C}\right)$. The obtained solution was filtered by $0.45 \mu \mathrm{m}$ milipore filter paper and the drug content was determined by taking absorbance using UV-Visible Spectrophotometer at 260 $\mathrm{nm}$. The amount of ketoprofen was calculated using the calibration curve in water. The Gibbs free energy of transfer $(\Delta G)$ of ketoprofen from pure water to the aqueous solution of carrier was also calculated as

$\Delta \mathrm{G}=-2.303 \mathrm{RT} \log \mathrm{S}_{\mathrm{o}} / \mathrm{S}_{\mathrm{s}}$

Where $S_{d} / S_{s}$ is the ratio of solubility of ketoprofen in aqueous solution of carrier to that of the same medium without carrier.

\section{In vitro drug release}

In vitro dissolution studies were performed using the USP type II dissolution apparatus. Dissolution studies of pure drug (ketoprofen), PM and solid dispersions containing ketoprofen equivalent to $10 \mathrm{mg}$ were conducted in $300 \mathrm{ml}$ phosphate buffer $(\mathrm{pH} 7.4)$ at $37 \pm 0.5^{\circ} \mathrm{C}$ with constant stirring rate of $50 \mathrm{rpm}$. The powders were dispersed over the dissolution medium. Aliquots of sample (5ml) was withdrawn at different time intervals and replaced with an equal amount of the dissolution medium to maintain a constant volume. Samples 
were filtered through $0.45 \mu \mathrm{m}$ milipore filters and analyzed by UV-visible spectrophotometer at $260 \mathrm{om}$. The mechanism of drug release from the solid dispersion was determined by fitting the release data to several models like zeroorder, first- order, Higuchi and Korsmeyer-Peppas plots.

\section{RESULTS AND DISCUSSION}

The BSA-Ketoprofen solid dispersions were prepared using 2-factor, 3-level central composite experimental design using concentration of BSA $\left(\mathrm{X}_{1}\right)$ and ketoprofen $\left(\mathrm{X}_{2}\right)$ as independent variable. Solubility $\left(\mathrm{Y}_{1}\right)$ and \% release $\left(\mathrm{Y}_{2}\right)$ were chosen as dependent or response variables.

\section{Drug content of formulations}

Ketoprofen assay data for content uniformity of the drug in different batches of SD and PM are given in Table 1. From the data it is clearly indicated that the drug content in the formulated batches of SD and PM was within the range of the theoretical amount, indicating the method used for formulation was suitable and reproducible in nature.

\section{Fourier Transform Infrared Spectroscopy (FT-IR)}

Figure 1 exhibits the FTIR spectra of ketoprofen, BSA, SD and PM in the frequency region from 4000 to $450 \mathrm{~cm}^{-1}$. The spectra of ketoprofen showed characteristic absorption band at $2979.54 \mathrm{~cm}^{-1}$ due to $-\mathrm{CH}$ stretching. The peak appearing at $1653.74 \mathrm{~cm}^{-1}$ can be ascribed to $-\mathrm{C}=\mathrm{O}$ stretching, while peak appearing at $1598.70 \mathrm{~cm}^{-1}$ is due to $-\mathrm{C}=\mathrm{C}$ stretching. The absorption band at $1445.03 \mathrm{~cm}^{-1}$ and $866.30 \mathrm{~cm}^{-1}$ can be attributed to $-\mathrm{C}-\mathrm{C}$ deformation and $-\mathrm{CH}$ deformation for substituted aromatic (out of plane), respectively. The spectra of Bovine serum albumin (BSA) present the characteristic absorption band of $-\mathrm{NH}$ bending vibration appearing at $3407.98 \mathrm{~cm}^{-1}$, peak of $-\mathrm{C}=\mathrm{O}$ stretching vibrations of the peptide bond (amide I band) appeared at $1651.51 \mathrm{~cm}^{-1}$ while peak appearing at $1546.85 \mathrm{~cm}^{-1}$ can be ascribed to $-\mathrm{NH}$ bending vibration / -CN stretching vibration (amide II band). The peak at $1239.16 \mathrm{~cm}^{-1}$ may be due to - $\mathrm{CN}$ stretching vibration / -NH bending vibration (amide III band). The spectra of SD revealed the characteristic peak appearing at $2962.52 \mathrm{~cm}^{-1}$ that can be ascribed to $-\mathrm{CH}$ stretching, the peak at $1654.55 \mathrm{~cm}^{-1}$ may be attributed to $-\mathrm{C}=\mathrm{O}$ stretching while the peak at $1541.32 \mathrm{~cm}^{-1}$ is attributed to $-\mathrm{C}=\mathrm{C}$ stretching and peaks appearing at $827.97 \mathrm{~cm}^{-1}, 703.55 \mathrm{~cm}^{-1}$ and $619.18 \mathrm{~cm}^{-1}$ are of fingerprint region. The spectra of $\mathrm{PM}$ revealed that the characteristic peak appearing at $2930.49 \mathrm{~cm}^{-1}$ can be ascribed to --CH stretching, the peak at $1656.27 \mathrm{~cm}^{-1}$ may be attributed to $-\mathrm{C}=\mathrm{O}$ stretching, while the peak at $1534.82 \mathrm{~cm}^{-1}$ is attributed to $-\mathrm{C}=\mathrm{C}$ stretching and peaks at $968.27 \mathrm{~cm}^{-1}, 827.92 \mathrm{~cm}^{-1}, 717.55 \mathrm{~cm}^{-1}$ and 
$618.92 \mathrm{~cm}^{-1}$ are of fingerprint region. The characteristic peaks of ketoprofen also seen in the SD and PM that indicate that ketoprofen is present in the solid dispersion and physical mixture.

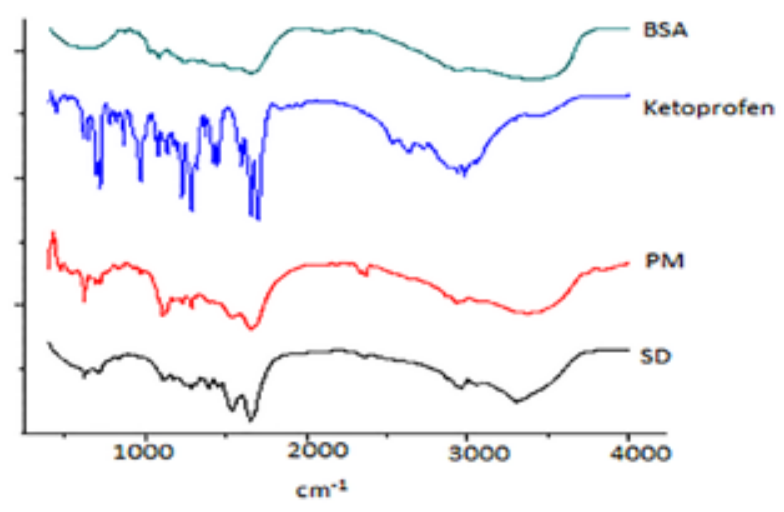

Figure 1. FT-IR spectra of ketoprofen, bovine serum albumin (BSA), physical mixture (PM) and solid dispersion (SD).

\section{X-ray diffraction analysis (XRD)}

The solid state of ketoprofen in the solid dispersion was examined using XRD (Figure 2). The XRD spectra of BSA is of typical amorphous material whereas the ketoprofen showed characteristics sharp peaks at $18.35^{\circ} \mathrm{C}$ and $23.069^{\circ} \mathrm{C}$ $2 \theta$ owing to its crystallinity. The X-Ray diffractogram of PM showed certain peaks corresponding to crystalline ketoprofen. However, XRD spectra of BSAketoprofen solid dispersion contain no sharp peaks thus unveiling amorphous characteristics of the final product.

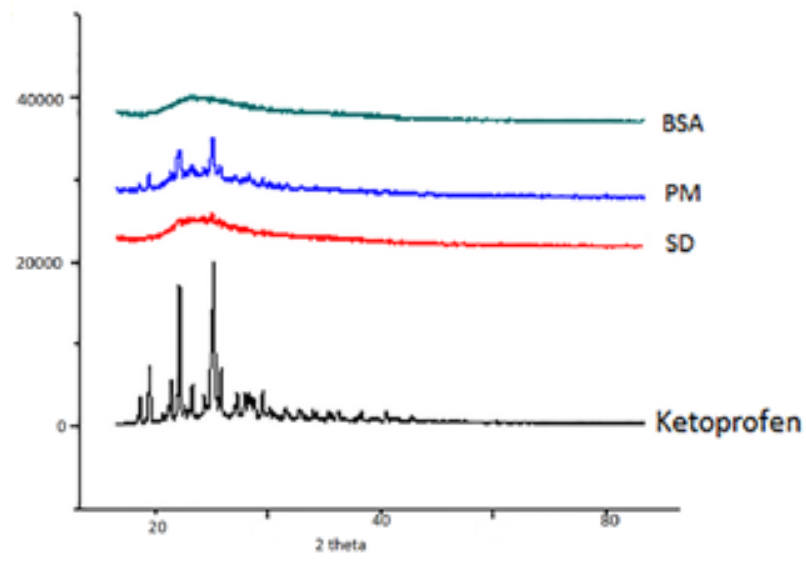

Figure 2. XRD spectra of bovine serum albumin (BSA), physical mixture (PM), solid dispersion (SD) and ketoprofen. 


\section{Differential scanning calorimetry (DSC)}

Figure 3 displays the DSC thermogram of ketoprofen, solid dispersion (SD), physical mixture (PM) and bovine serum albumin (BSA). The thermogram of BSA appeared as broad peak at $94.26^{\circ} \mathrm{C}$ that is of typical amorphous material. The thermogram of ketoprofen showed a sharp peak at $93.08^{\circ} \mathrm{C}$ that corresponds to its melting point. A peak with decreased intensity at around $99.58^{\circ} \mathrm{C}$ is also seen in BSA-Ketoprofen physical mixture indicating the crystalline state of drug in the physical mixture. However, amorphous property of the solid dispersion can be inferred from the broad endotherm and disappearance of sharp peak in thermogram of SD.

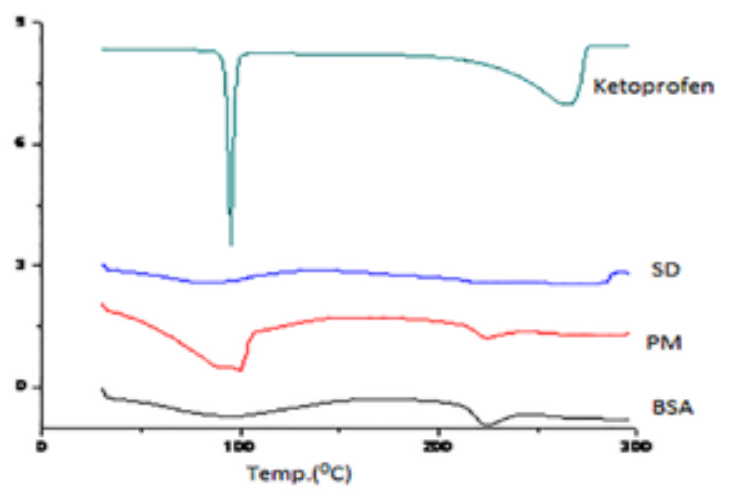

Figure 3. DSC thermogram of ketoprofen, solid dispersion (SD), physical mixture (PM) and bovine serum albumin (BSA)

\section{Scanning electron microscopy (SEM)}

Figure 4 exhibits the scanning electron micrograph showing surface morphology of solid dispersion. The SEM micrograph of SD shows irregular structure with porous and rough surface.

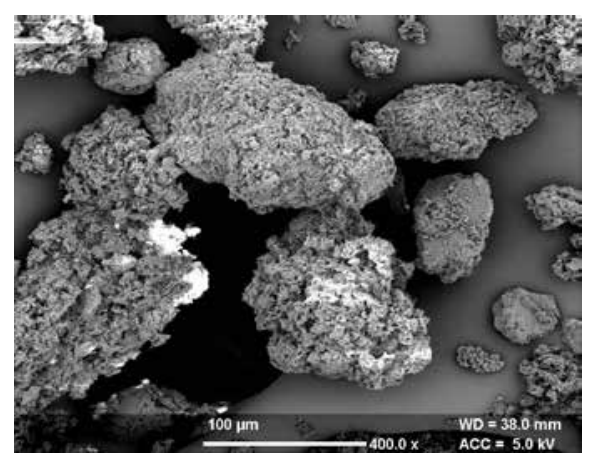

Figure 4. SEM photomicrographs

of solid dispersion 


\section{Solubility}

The different batches of SD were prepared containing BSA (1-2\%) and ketoprofen (0.1-0.5\%) as per the design protocol (Table 1). The pure ketoprofen dispensed a solubility of $18.79 \mu \mathrm{g} / \mathrm{ml}$ in water at room temperature whereas the physical mixture showed solubility of $34 \mu \mathrm{g} / \mathrm{ml}$. The physical mixture presented solubility higher than the pure drug because of the BSA. However, the solid dispersion conferred solubility values ranging from $38-58 \mu \mathrm{g} / \mathrm{ml}$. This increase may be due to formation of soluble complex between drug and BSA whereas the lower solubility in case of physical mixture as compared to SD may be explained on the basis of results obtained from DSC and XRD studies revealing that ketoprofen is still present in crystalline state.

Table 1. Solubility, in-vitro release, drug content and Gibb's free energy of different batches.

\begin{tabular}{|c|c|c|c|c|c|c|}
\hline Batch & $\begin{array}{l}\text { Conc. Of } \\
\text { BSA (\%) } \\
\left(X_{1}\right)\end{array}$ & $\begin{array}{l}\text { Conc. Of } \\
\text { ketoprofen } \\
(\%)\left(X_{2}\right)\end{array}$ & $\begin{array}{l}\text { Solubility } \\
(\mu \mathrm{g} / \mathrm{ml}) \\
\left(Y_{1}\right)\end{array}$ & $\begin{array}{l}\% \text { release } \\
\text { in } 60 \text { min. } \\
\left(Y_{2}\right)\end{array}$ & $\begin{array}{l}\text { Drug } \\
\text { content } \\
(\%)\end{array}$ & $\begin{array}{l}\Delta \mathrm{G} \\
(\mathrm{KJ} / \mathrm{Mol})\end{array}$ \\
\hline SD1 & 1 & 0.5 & $43 \pm 0.8$ & $77.81 \pm 0.1$ & $97.78 \pm 0.14$ & -1.8 \\
\hline SD2 & 1.5 & 0.3 & $51 \pm 0.25$ & $89.67 \pm 0.1$ & $98.17 \pm 0.08$ & -2.2 \\
\hline SD3 & 2 & 0.3 & $56 \pm 0.28$ & $92.5 \pm 0.1$ & $99 \pm 0.2$ & -2.4 \\
\hline SD4 & 1.5 & 0.3 & $51 \pm 0.25$ & $85.44 \pm 0.21$ & $97.89 \pm 0.61$ & -2.2 \\
\hline SD5 & 1.5 & 0.3 & $53 \pm 0.3$ & $86.18 \pm 0.1$ & $97.96 \pm 0.3$ & -2.3 \\
\hline SD6 & 1 & 0.3 & $40 \pm 0.1$ & $76.33 \pm 0.23$ & $97.39 \pm 0.2$ & -1.7 \\
\hline SD7 & 2 & 0.5 & $58 \pm 0.22$ & $93.2 \pm 0.2$ & $99.42 \pm 0.16$ & -2.5 \\
\hline SD8 & 1.5 & 0.3 & $5 \pm 0.6$ & $88.37 \pm 0.17$ & $98.05 \pm 0.1$ & -2.3 \\
\hline SD9 & 1.5 & 0.5 & $54 \pm 0.32$ & $91.11 \pm 0.1$ & $98.21 \pm 0.1$ & -2.3 \\
\hline SD10 & 1.5 & 0.1 & $47 \pm 0.71$ & $80.11 \pm 0.3$ & $97.56 \pm 0.25$ & -2.0 \\
\hline SD11 & 1 & 0.1 & $38 \pm 0.20$ & $72.24 \pm 0.1$ & $97 \pm 0.28$ & -1.5 \\
\hline SD12 & 2 & 0.1 & $48 \pm 0.16$ & $85.21 \pm 0.28$ & $97.88 \pm 0.22$ & -2.1 \\
\hline SD13 & 1.5 & 0.3 & $50 \pm 0.28$ & $86.33 \pm 0.16$ & $98.01 \pm 0.11$ & -2.2 \\
\hline PM & 2 & 0.5 & $34 \pm 0.49$ & $42 \pm 0.22$ & $98.34 \pm 0.18$ & -1.3 \\
\hline Ketoprofen & & & $18.79 \pm 0.29$ & $26 \pm 0.17$ & & \\
\hline
\end{tabular}

Table 1 shows the results of solubility of different batches of solid dispersions prepared as per the design protocol. The responses generated were fitted into various polynomial models using experimental design. The response solubility was fitted best into quadratic model with none transformation of the data. The adjusted polynomial equation obtained for the solubility $\left(\mathrm{Y}_{1}\right)$ shown in equation (i) with determination correlation $\left(\mathrm{R}^{2}\right)$ of 0.9740 . 
$\mathrm{Y}_{1}=51.62+6.83 \mathrm{X}_{1}+3.67 \mathrm{X}_{2}+1.25 \mathrm{X}_{1} \mathrm{X}_{2}-3.6 \mathrm{X}_{1}^{2}-1.17 \mathrm{X}_{2}^{2}$

Table 2 summarizes the results of ANOVA on the response surface model. The polynomial model was found to be significant $(\mathrm{p}<0.05)$ with non-significant lack of fit ( $p>0.05$ ). The good correlation between the experimental and predicted response is indicated by higher value of $\mathrm{R}^{2}(>0.9)$. Adequate precision that measures the signal to noise ratio was much above the required value of 4 , indicating adequate signal and model fit to navigate the design space. Fig. 5 (a) display the combined effect of concentration of BSA \& Ketoprofen on solubility. It can be inferred from the plots that there exists a curvilinear relationship between independent and dependent variables. It is inferred from the plot that higher level of BSA \& ketoprofen results in increase in solubility.

To attain stability a natural tendency to acquire minimum Gibbs energy is always there. The plot of Gibbs free energy against varying concentration of BSA and ketoprofen (Fig. $5 \mathrm{c}$ ) construed that the process is more favorable at higher level of BSA and ketoprofen possessing minimum value of $\Delta \mathrm{G}$. Further, all the values of $\Delta \mathrm{G}$ are negative (Table 1 ) at all levels of carrier demonstrating spontaneity of drug solubilization process.

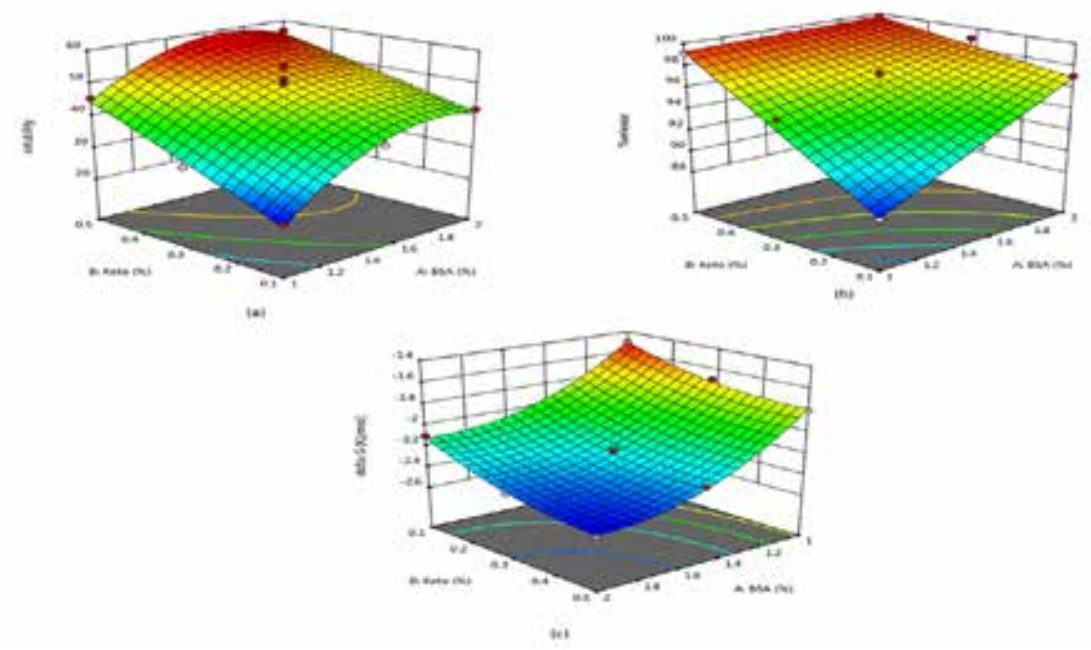

Figure 5. $(a, b, c)$ Response surface plots showing effect of concentration of BSA \& Ketoprofen on solubility (Y1), in-vitro release (Y2) and Gibb's free energy. 


\section{In vitro drug release}

Table 1 shows the in vitro drug release data at $60 \mathrm{~min}$. From these results, it is observed that only $26 \%$ of ketoprofen was released in $1 \mathrm{hr}$ from drug solution and $42 \%$ from the PM whereas different batches of SD show 72.24 to $98.2 \%$ release of ketoprofen in $1 \mathrm{hr}$ study. The higher percentage release of drug in case of SD as compared to pure drug and PM may be related to the solubility data. As previously mentioned that the BSA form the soluble complex with the drug and thus increasing drug wettability and leads to a better solubility and thus better rate of drug release.

The polynomial equation obtained for the dependent variable $\mathrm{Y}_{2}$ (in vitro release) is shown in equation (ii)

$\mathrm{Y}_{2}=87.30+7.42 \mathrm{X}_{1}+4.09 \mathrm{X}_{2}+0.605 \mathrm{X}_{1} \mathrm{X}_{2}-3.13 \mathrm{X}_{1}^{2}-1.93 \mathrm{X}_{2}^{2}$

Table 2 summarizing the results of ANOVA on response surface model (fitted best in quadratic model after none transformation of the data). The responses generated were fitted into various polynomials models using the experimental design. It was observed that response in-vitro release $\left(\mathrm{Y}_{2}\right)$ fitted best into quadratic response surface model.

Table 2. Model summary statistic

\begin{tabular}{|c|c|c|c|c|c|c|c|}
\hline \multirow{2}{*}{ Response factor } & \multicolumn{5}{|c|}{ Model } & \multicolumn{2}{c|}{ Lack of fit } \\
\cline { 2 - 8 } & F-value & Prob.>F & $R^{2}$ & $\begin{array}{c}\text { Adeq. } \\
\text { prec. }\end{array}$ & C.V. (\%) & F-value & Prob.>F \\
\hline$Y_{1}$ & 52.36 & $\begin{array}{c}< \\
0.0001\end{array}$ & 0.9740 & 24.2411 & 2.58 & 0.7745 & 0.5659 \\
\hline$Y_{2}$ & 34.42 & $\begin{array}{c}< \\
0.0001\end{array}$ & 0.9609 & 20.0699 & 1.99 & 0.8202 & 0.5467 \\
\hline
\end{tabular}

The polynomial model was found to be significant $(\mathrm{p}<0.05)$ with non-significant lack of fit ( $\mathrm{p}>0$. 05). The higher value of $\mathrm{R}^{2}$ ( $>0.9$ ) pertinent good correlation between the experimental and predicted response. Adequate precision that estimates the signal to noise ratio was much above the required value of 4 , indicating adequate signal and model fit to navigate the design space. Figure 5 (b) display the combined effect of concentration of BSA \& ketoprofen on \% release that exhibited a linear relationship between independent and dependent variables, suggested that higher level of BSA \& ketoprofen favours the expedited release. The numerical optimization tool using desirability approach was employed to prepare solid dispersion. The optimization of independent variables was done with constraints of maximum solubility and maximum \% release. The 
parameters suggested by the design were concentration of BSA (1.950\%) \& concentration of ketoprofen (0.480\%) that provide SD with solubility of $58 \mu \mathrm{g} / \mathrm{ml}$ (predicted value $58.159 \mu \mathrm{g} / \mathrm{ml}$ ) and \% release 93.2\% (predicted value 94.05\%). The closer agreement between predicted and observed values indicated the high prognostic ability of the model. Figure 6 displays the in vitro release profile of ketoprofen as pure drug and from the optimised batch of formulation.

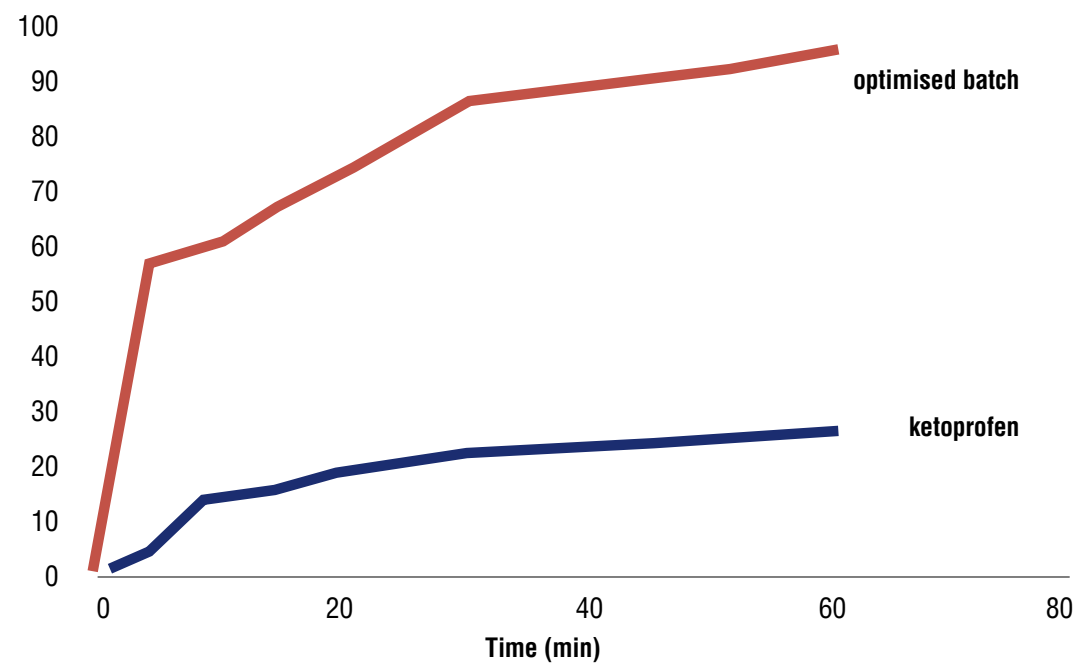

Figure 6. In-vitro release profile of pure ketoprofen and solid dispersion (optimized batch).

\section{CONCLUSION}

The solid dispersion has been the synonym for the enhancement of solubility of poorly water-soluble drugs. In this study, Bovine serum albumin (BSA) is used as solubility enhancer of ketoprofen (a model drug). The solid dispersion containing BSA and ketoprofen was prepared using 2-factor-3-level central composite experimental design. The preparation of SD was characterized by FTIR, XRD, DSC and SEM studies. The DSC and XRD studies demonstrated the amorphous nature of the solid dispersion. Thereby, solid dispersion exhibited a fast release and enhanced solubility as compared to pure drug and physical mixture. Thus, overall study rendered the suitability of lyophilized BSA solid dispersion in improving the solubility of poorly water-soluble drug.

\section{ACKNOWLEDGEMENTS}

The authors are highly grateful to DST-PURSE New Delhi, Sanction no. SR/ PURSE 2/40 (G) programme, Guru Jambheshwar University of Science \& Technology, Hisar. 


\section{REFERENCES}

1. Kaur, S., Jena, S. K., Samal, S. K., Saini, V., \& Sangamwar, A. T. Freeze dried solid dispersion of exemestane: A way to negate an aqueous solubility and oral bioavailability problems. European Journal of Pharmaceutical Sciences, 2017, 107, 54-61.

2. Sherje, A. P., Murahari, M., Suvarna, V., \& Patel, K. Study on effect of L-arginine on solubility and dissolution of Zaltoprofen: Preparation and characterization of binary and ternary cyclodextrin inclusion complexes. Chemical Physics Letters, 2018, 694, 120-128.

3. Lim, L. M., Cheow, W. S., \& Hadinoto, K. Re-evaluating the presumed superiority of amorphous nanoparticles over amorphous microscale solid dispersion in solubility enhancement of poorly soluble drugs. European Journal of Pharmaceutical Sciences, 2017, 109, 455-463.

4. Vithani, K., Hawley, A., Jannin, V., Pouton, C., \& Boyd, B. J. Solubilisation behaviour of poorly water-soluble drugs during digestion of solid SMEDDS. European Journal of Pharmaceutics and Biopharmaceutics, 2018, 130, 236-246.

5. Aloisio, C., Antimisiaris, S. G., \& Longhi, M. R. Liposomes containing cyclodextrins or meglumine to solubilize and improve the bioavailability of poorly soluble drugs. Journal of Molecular Liquids, 2017, 229, 106-113.

6. Dwichandra Putra, O., Umeda, D., Fujita, E., Haraguchi, T., Uchida, T., Yonemochi, E., \& Uekusa, H. Solubility Improvement of Benexate through Salt Formation Using Artificial Sweetener. Pharmaceutics, 2018, $10(2), 64$.

7. Strickley, R. G. Solubilizing excipients in oral and injectable formulations. Pharmaceutical research, 2004, 21(2), 201-230.

8. Priemel, P. A., Laitinen, R., Grohganz, H., Rades, T., \& Strachan, C. J. In situ amorphisation of indomethacin with Eudragit ${ }^{\circledR}$ E during dissolution. European Journal of Pharmaceutics and Biopharmaceutics, 2013, 85(3), 1259-1265.

9. Sekiguchi, K., \& Obi, N. Studies on Absorption of Eutectic Mixture. I. A Comparison of the Behavior of Eutectic Mixture of Sulfathiazole and that of Ordinary Sulfathiazole in Man. Chemical and Pharmaceutical Bulletin, 1961, 9(11), 866-872.

10. Chiou, W. L., \& Riegelman, S. Preparation and dissolution characteristics of several fast-release solid dispersions of griseofulvin. Journal of Pharmaceutical Sciences, 1969, 58(12), 1505-1510.

11. Özkan, Y., Doğanay, N., Dikmen, N., \& Işımer, A. (2000). Enhanced release of solid dispersions of etodolac in polyethylene glycol. Il Farmaco, 2000, 55(6-7), 433-438.

12. Ghosh, I., Snyder, J., Vippagunta, R., Alvine, M., Vakil, R., Tong, W. Q. T., \& Vippagunta, S. Comparison of HPMC based polymers performance as carriers for manufacture of solid dispersions using the melt extruder. International Journal of Pharmaceutics, 2011, 419(1-2), 12-19.

13. Motallae, S., Taheri, A., \& Homayouni, A. Preparation and characterization of solid dispersions of celecoxib obtained by spray-drying ethanolic suspensions containing PVP-K30 or isomalt. Journal of Drug Delivery Science and Technology, 2018, 46, 188-196.

14. Zecevic, D. E., Meier, R., Daniels, R., \& Wagner, K. G. Site specific solubility improvement using solid dispersions of HPMC-AS/HPC SSL-Mixtures. European Journal of Pharmaceutics and Biopharmaceutics, 2014, 87(2), 264-270.

15. Miyazaki, T., Aso, Y., Yoshioka, S., \& Kawanishi, T. Differences in crystallization rate of nitrendipine enantiomers in amorphous solid dispersions with HPMC and HPMCP. Interna- 
tional Journal of Pharmaceutics, 2011, 407(1-2), 111-118.

16. Babu, G. M. M., Prasad, C. D., \& Murthy, K. R. Evaluation of modified gum karaya as carrier for the dissolution enhancement of poorly water-soluble drug nimodipine. International journal of Pharmaceutics, 2002, 234(1-2), 1-17.

17. Van Drooge, D. J., Hinrichs, W. L. J., \& Frijlink, H. W. Anomalous dissolution behaviour of tablets prepared from sugar glass-based solid dispersions. Journal of Controlled Release, 2004, 97(3), 441-452.

18. Yadav, P. S., Kumar, V., Singh, U. P., Bhat, H. R., \& Mazumder, B. Physicochemical characterization and in vitro dissolution studies of solid dispersions of ketoprofen with PVP K3O and d-mannitol. Saudi Pharmaceutical Journal, 2013, 21(1), 77-84.

19. Mohammadi, G., Hemati, V., Nikbakht, M. R., Mirzaee, S., Fattahi, A., Ghanbari, K., \& Adibkia, K. In vitro and in vivo evaluation of clarithromycin-urea solid dispersions prepared by solvent evaporation, electrospraying and freeze-drying methods. Powder Technology, 2014, 257, 168-174.

20. de los Santos, C. J. J., Pérez-Martínez, J. I., Gómez-Pantoja, M. E., \& Moyano, J. R. Enhancement of albendazole dissolution properties using solid dispersions with Gelucire 50/13 and PEG 1500o. Journal of Drug Delivery Science and Technology, 2017, 42, 261-272.

21. Singh, G., Pai, R. S., \& Devi, V. K. Effects of the Eudragit and Drug coat on the release behaviour of poorly soluble drug by solid dispersion technique. International Journal of Pharmaceutical Sciences and Research, 2011, 2(4), 816.

22. Prajapati, S. T., Gohel, M. C., \& Patel, L. D. Studies to enhance dissolution properties of carbamazepine. Indian Journal of Pharmaceutical Sciences, 2007, 69(3), 427.

23. Wren, S. A. C., Alhusban, F., Barry, A. R., \& Hughes, L. P. Mechanistic understanding of the link between Sodium Starch Glycolate properties and the performance of tablets made by wet granulation. International Journal of Pharmaceutics, 2017, 529(1-2), 319-328.

24. Modi, A. \& Tayade, P. Enhancement of dissolution profile by solid dispersion (kneading) technique. AAPS pharmscitech, 2oo6, 7(3), E87.

25. Yu, Z., Yu, M., Zhang, Z., Hong, G., \& Xiong, Q. Bovine serum albumin nanoparticles as controlled release carrier for local drug delivery to the inner ear. Nanoscale research letters, 2014, 9(1), 343.

26. Ghuman, J., Zunszain, P. A., Petitpas, I., Bhattacharya, A. A., Otagiri, M., \& Curry, S. Structural basis of the drug-binding specificity of human serum albumin. Journal of molecular biology, 2005, 353(1), 38-52.

27. Peters Jr, T. All about albumin: biochemistry, genetics, and medical applications. Academic press. 1995.

28. Evans, T. W. albumin as a drug-biological effects of albumin unrelated to oncotic pressure. Alimentary Pharmacology \& Therapeutics, 2002, 16, 6-11.

29. Liu, Z., \& Chen, X. Simple bioconjugate chemistry serves great clinical advances: albumin as a versatile platform for diagnosis and precision therapy. Chemical Society Reviews, 2016, 45(5), 1432-1456.

30. Urien, S., Tillement, J. P., \& Barré, J. The significance of plasma-protein binding in drug research (pp. 189-197). 20o1, Wiley VCH: Zürich, Switzerland. 